УДК 629.436

DOI 10.47049/2226-1893-2020-2-120-129

\title{
ПОЛІПШЕННЯ ЕКСПЛУАТАЦІЙНИХ ПОКАЗНИКІВ СУДНОВИХ ДИЗЕЛІВ ШЛЯХОМ КАВІТАЦЙНОЇ ОБРОБКИ ПАЛИВА
}

\author{
В.Г. Солодовніков \\ кандидат технічних наук, доцент \\ Національний університет «Одеська морська академія»
}

Анотація. Розглянуто можливість поліпшення експлуатаційних показників суднових дизелів шляхом кавітаџійної обробки палива. Наведена схема системи підготовки палива з урахуванням можливості додаткового використання кавітаційної обробки палива. Вказано, щяо кавітаційна обробка палива сумісно з додатковою подачею повітря в зону кавітаиії сприяє розриванню $C-C$ та $C-S$ зв'язків палива. Експериментально встановлено, шо при иьому забезпечується 3,2-4,7-е кратне зниження зносу поршневих кілець $і$ ииліндрових втулок дизеля, а також покрашується технічний стан ииліндропоршневої групи дизеля.

Ключові слова: судновий дизель, підготовка палива, кавітаційна обробка палива, сірчистий знос ииліндропоршневої групи.

УДК 629.436

DOI 10.47049/2226-1893-2020-2-120-129

\section{УЛУЧШЕНИЕ ЭКСПЛУАТАЦИОННЫХ ПОКАЗАТЕЛЕЙ СУДОВЫХ ДИЗЕЛЕЙ ПУТЕМ КАВИТАЦИОННОЙ ОБРАБОТКИ ТОПЛИВА}

\section{В.Г. Солодовников}

кандидат технических наук, доцент

Национальный университет «Одесская морская академия»

Аннотация. Рассмотрена возможность улучшения эксплуатационных показателей судовых дизелей путем кавитационной обработки топлива. Приведенна схема системы подготовки топлива с учетом возможности дополнительного использования кавитащионной обработки топлива. Указано, что кавитационная обработка топлива совместно с дополнительной подачей воздуха в зону кавитации способствует разpыву C-C и C-S связей топлива. Экспериментально установлено, что при этом обеспечивается 3,2-4,7-е кратное снижение износа поршневых колеи и иилиндровых втулок дизеля, а также улучшается техническое состояние иилиндропоршневой группы дизеля.

Ключевые слова: судовой дизель, подготовка топлива, кавитационная обработка топлива, сернистый износ ичилиндропоршневой группь.

() Солодовніков В.Г., 2020 
UDC 629.436

DOI 10.47049/2226-1893-2020-2-120-129

\title{
IMPROVING THE PERFORMANS OF MARINE DIESEL ENGINES BY CAVITATION TREATMENT OF THE FUEL
}

\author{
V. Solodovnikov \\ Candidate of Technical Sciences, Associate Professor \\ National University «Odessa Maritime Academy»
}

\begin{abstract}
It is stated that medium-speed diesels are a part of any ship power plants, their work is provided by different systems. An important role in the complex of conversion of potential energy of the fuel into the effective power of the diesel is performed by the fuel preparation system. The efficiency of its operation is determined by the change in the structural characteristics and operational properties of the fuel before and after the process of its processing. It is shown that the highest energy costs in the preparation of fuel are associated with the removal of various impurities. (mechanical, water, sulfuric). It is established that the sulfur content of the fuel is the cause of the sulfuric deterioration of the main elements of a medium-speed diesel-cylinder bushes and piston rings. The possibility of improving the performance of marine diesel engines by cavitation fuel treatment is considered. The scheme of the fuel preparation system is given taking into account the possibility of additional use of cavitation fuel treatment. An ultrasonic installation (which provides cavitation fuel treatment with optimum frequency and amplitude) is proposed. It is stated that the cavitation treatment of the fuel together with the additional air supply to the cavitation zone contributes to the breaking of $C-C$ and $C$-S bonds of the fuel. The experimental results for determining the wear of the cylinder bushings and piston rings for different fuel preparation options are given: for conventional equipment, using an ultrasonic unit, using an ultrasonic unit and additional air supply to the cavitation zone. It has been experimentally established that this ensures 3,2-4,7-fold reduction in wear of piston rings and diesel cylinder bushes, and also improves the technical condition of the cylinder group of the diesel engine.
\end{abstract}

Keywords: marine diesel, fuel preparation, cavitation fuel treatment, sulfuric wear of the cylinder piston group.

Постановка проблеми в загальному вигляді. Середньообертові дизелі (СОД) входять до складу будь-яких суднових енергетичних установок (СЕУ). Важливу роль у комплексі перетворення потенційної енергії палива на ефективну потужність дизеля виконує система паливопідготовки, ефективність роботи якої визначається зміною структурних характеристик та експлуатаційних властивостей палива до і після процесу його обробки. Найбільші енергетичні витрати в системі паливопідготовки пов'язані з видаленням із палива різних домішок, у тому числі сірчистих [1]. 
Завдання підвищення енергоефективності та економічності СЕУ розв'язується не тільки за рахунок зростання циліндрової потужності і зниження питомої витрати палива, але й за рахунок використання в суднових двигунах внутрішнього згоряння (ДВЗ) палив підвищеної в'язкості. Традиційно подібні палива використовувалися в малообертових дизелях (МОД), що характеризуються підвищеним часом, відведеним на впорскування палива в циліндр, його самозаймання та подальше згоряння. На даний час високов'язкі палива використовуються і в (СОД), що мають більш короткі фази сумішоутворення і згоряння. При цьому (через зсув процесу згоряння на лінію розширення) можливе погіршення технічного стану та експлуатаційних характеристик дизеля. Це підвищує актуальність розв'язання завдань щодо забезпечення якісної підготовки палива для подібного класу дизелів [2].

Аналіз останніх досліджень і публікацій. Використання важких палив у суднових дизелях викликало ряд проблем, основними з яких $\epsilon$ підвищені зноси деталей циліндропоршневої групи і паливної апаратури, нагар на всіх елементах дизеля, що контактують 3 продуктами згоряння, збільшення кількості відходів під час паливопідготовки [3]. Розв'язання завдання щодо зниження сірчистого зносу деталей двигунів на даний час повністю виконано для МОД, які мають окрему циліндрову систему змащування. При цьому залишається лише знайти оптимальне співвідношення між вмістом сірки в паливі і змістом лужних присадок у мастилі [4]. Суднові СОД мають загальну циркуляційну систему змащування, застосування мастил 3 підвищеним вмістом лугу в даному випадку недоцільно як 3 економічних причин (у зв'язку 3 їхньою високою вартістю), так і з огляду на їх гірші експлуатаційні параметри (зокрема меншої здатності чинити опір нормальним навантаженням) [5] . Тому для СОД єдиним способом боротьби з наслідком застосування сірчистого палива $\epsilon$ його додаткова обробка перед подачею в циліндр, що сприяє згодом зниженню сірчистого зносу [6]. При цьому необхідно враховувати, що вирішення проблеми 3 видалення сірчистих домішок із палива повинно бути комплексним, тому що будь-яка фізична дія на паливо призводить до зміни практично всіх його компонентів.

Постановка завдання. Таким чином, незважаючи на широкий спектр наукових досліджень, що спрямовані на розв'язання завдання 3 підвищення ефективності використання в СЕУ важких палив, існує невирішена проблема, якою $є$ експлуатація суднових СОД на паливах 3 підвищеною в'язкістю та максимально можливим вмістом сірчистих сполук.

Виклад основного матеріалу дослідження. Для успішного застосування в'язких, високо-сірчистих палив у суднових СОД необхідне розв'язання комплексу організаційно-технічних завдань від прийому палива на борт судна до його спалювання в циліндрі дизеля [7]. Система паливопідготовки повинна забезпечувати захист дизеля під час його 
роботи 3 використанням сірчистих палив на всьому діапазоні експлуатаційних режимів.

Одним із методів паливопідготовки, що сприяє зменшенню шкідливого впливу сірки на деталі ДВ3, є кавітаційна обробка палива ультразвуком. Паливо для суднових дизелів із точки зору дисперсної системи має в'язкість, що не підкоряється законам Ньютона, Пуазейля, Стокса, тому що довгі, безладно розташовані молекули парафіну і смол, які входять до іiі складу, утворюють гнучкий ланцюжок. У зв'язку з цим система надає значний опір силам зсуву. Кавітація руйнує безперервний ланцюжок та розриває зв'язок між окремими частинами молекул. Таким чином, кавітація впливає на зміну структурної в'язкості, тобто на розрив Ван-дер-Ваальсових зв'язків всередині палива, сприяє поліпшенню дисперсних якостей палива, призводить до додаткової активації його вуглеводневих складових і розщепленню C-C i C-S зв'язків. Одним із варіантів застосування кавітаційної обробки палива $€$ дообладнання штатних систем паливопідготовки додатковими модулями, які здійнюють цей процес [8]. Таким модулем була доукомплектована система паливопідготовки суднових COД 6VDS18, що мають номінальну потужність 390 кВт при частоті обертання колінчастого вала 750 об/хв та у кількості трьох штук складають суднову допоміжну енергетичну установку. Кожний дизель забезпечений автономною системою подачі палива, що дає можливість прово-дити дослідження для окремого дизеля 3 паливом, яке пройшло різні етапи підготовки. Паливна система одного 3 двигунів не піддавалася перекомплектації та експлуатувалася в «штатному» стані, при цьому даний дизель приймався за «контрольний». Паливо до двох інших дизелів подавалося після додаткової кавітаційної обробки. Під час проведення експерименту дизелі експлуатувалися на паливі HFO380. Фрагмент ділянки з дообладнанням паливної системи дизелів показаний на рис. 1 [9].

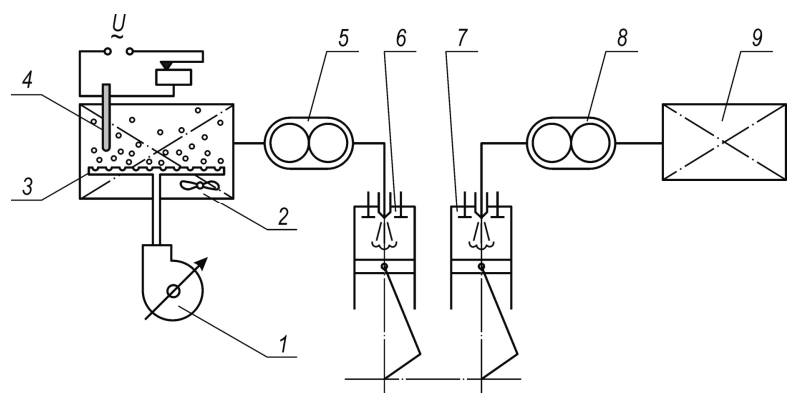

Рис. 1. Схема дообладнання системи подачі палива до двигунів (фрагмент):

1 - повітряний компресор; 2, 9 - паливні цистерни; 3 - повітряна магістраль;4 - ультразвукова установка; 5, 8-паливні насоси;

6, 7 - двигуни 
Двигун 7 був «контрольним» та експлуатувався в «штатному» режимі, при цьому паливо, пройшовши стандартну процедуру підготовки, подавалося до нього насосом 8 з цистерни 9. Двигуни 6 були «експериментальними». Паливо до них подавалося насосом 5 з цистерни 2, в якій паливо піддавалося впливу ультразвукових хвиль за допомогою генератора УЗГ-5М з магнітострикційним випромінювачем. При цьому для посилення кавітаційних явищ у нижній частині однієї з цистерн була прокладена додаткова повітряна магістраль 3 , нагнітання повітря до якої здійснювалося повітряним компресором 1. При цьому бульбашки повітря, що потрапляють в об'єм палива, були додатковими джерелами кавітаційних зон. Ультразвукова установка 4 експлуатувалася в режимі $I$ $=0,4 \mathrm{~A}$ із застосуванням магнітострикційного випромінювача в 22 кГц. Дані величини були визначені в попередніх лабораторних дослідженнях і забезпечували найкращі дисперсні показники палива. У паливній цистерні 2, в якій відбувалася ультразвукова обробка палива, додатково встановлювався лопатковий змішувач, що забезпечувало однорідність палива в повному обсязі.

Для забезпечення ідентичності експерименту для всіх дизелів проводилася їх попередня підготовка до випробувань. Умови експлуатації дозволяли послідовно протягом 40 годин виконати повну моточистку зазначених дизелів. При цьому на всіх дизелях замінювалися поршнева група (поршні і поршневі кільця) й основні елементи паливної системи високого тиску (прецизійні пари паливного насоса високого тиску плунжер - втулка і голка - розпилювач форсунки).

Протягом усього часу проведення експерименту здійснювався контроль часу роботи та експлуатаційного навантаження на дизелі. Для досягнення рівномірного розподілу часу роботи дизелів двигуни послідовно переводилися в режим stand-by. Відповідно до технології проведення експерименту різниця в часі роботи дизелів, а також в експлуатаційних навантаженнях на двигуни не перевищувала 4 \%, що, 3 огляду на енергоємність об'єктів, дозволяло вважати умови їх роботи ідентичними. Експлуатація двигунів проводилася на одному й тому ж сорті палива. При цьому засоби автоматичного контролю підтримували в'язкість палива незмінною протягом усього експерименту. Також ідентичним підтримувався сорт циркуляційного мастила, що забезпечує режими змащування, і його експлуатаційні характеристики. Дані заходи дозволили вважати, що виконання експерименту проходить в однакових умовах. Завданням дослідження було визначення зносу циліндрових втулок i верхнього поршневого кільця для «стандартного» палива i палива, що піддалося додатковій кавітаційної обробці. Вимірювання зносу проводилося для двох крайніх циліндрів, які, як відомо, більш ніж інші (центральні циліндри) схильні до цього явища [10]. Отримані при цьому значення усереднювалися. Крім того, дослідження тільки двох циліндрів суттєво скорочувало час монтажних робіт, який обмежувався 
умовами експлуатації. 3 цих же причин дослідження виконувалися після $170,360,580,780,1010$ годин роботи двигунів. За отриманими даними побудовані номограми (рис. 2), що характеризують зниження зносу розглянутих деталей під час викорис-тання додаткової ультразвукової кавітаційної обробки палива.

Висновки та перспективи подальших досліджень. Проведені експериментальні дослідження свідчать про те, що додаткова кавітаційна обробка високов'язкого палива (які можливо проводити як у паралельному, так і в послідовному варіанті) сприяють зниженню в 3,2-4,7 рази сірчистого зносу поршневих кілець і циліндрових втулок дизеля. При цьому найбільше зниження цього параметра спостерігається для поршневих кілець, що особливо актуально, враховуючи важливість даного вузла в забезпеченні не лише якісного перебігу процесів стиснення, згоряння i розширення, але й також надійності роботи трибосполучення поршень-втулка циліндра.

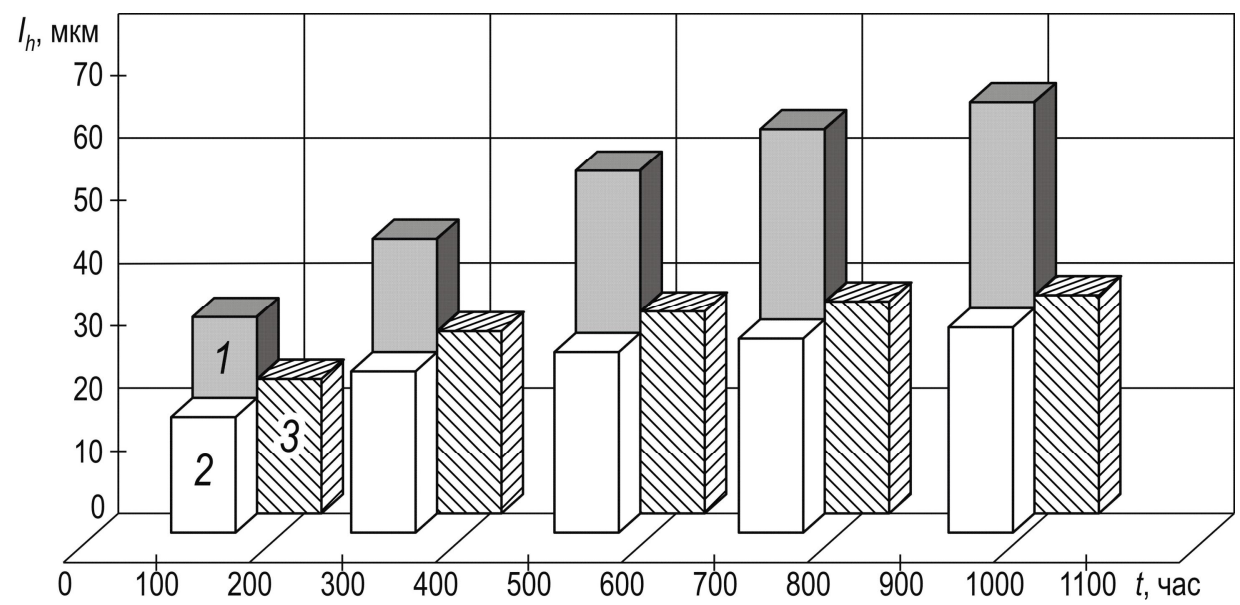

Рис. 2. Знос ииліндрових втулок суднового СОД 6VDS18 за різних умов експлуатащії:

1 - експлуатація у «штатному стані;

2 - експлуатаиія за умови кавітаиійної обробки палива;

3 - експлуатація за умови кавітаційної обробки палива з додатковою подачею повітря до зони кавітаиії

Використання кавітаційної обробки палива доцільно виконувати в сукупності зі стандартними методами паливопідготовки шляхом доповнення штатних схем спеціальним обладнанням. Оптимальні режими роботи цього обладнання визначаються попередніми дослідженнями, які (за умови розробки відповідних технологічних карт) можуть бути виконані безпосередньо судновою машинною командою [11]. 
ВІСНИК

ОДЕСЬКОГО НАЦІОНАЛЬНОГО

МОРСЬКОГО УНІВЕРСИТЕТУ

№ 2 (62), 2020
HERALD

OF THE ODESSA NATIONAL

MARITIME UNIVERSITY № 2 (62), 2020

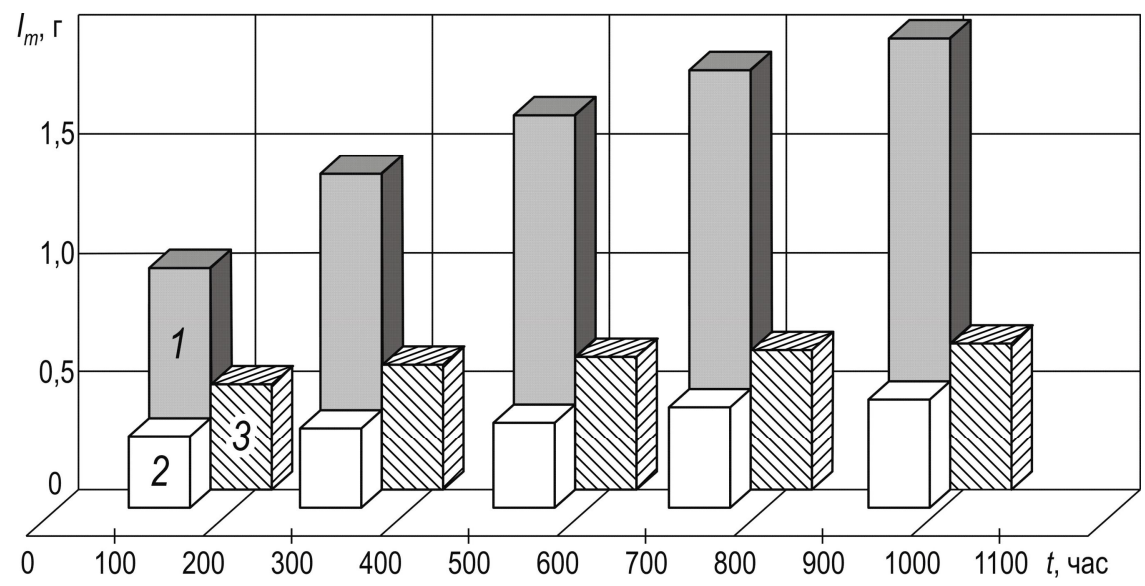

Рис. 3. Знос поршневих кілець суднового СОД 6VDS18 за різних умов експлуатації:

1 - експлуатація у «штатному стані;

2 - експлуатація за умови кавітаційної обробки палива;

3 - експлуатація за умови кавітаційної обробки палива з додатковою подачею повітря до зони кавітачіï

\section{СПИСОК ЛІТЕРАТУРИ}

1. Сагин С.В. Применение ультразвуковой обработки топлива для снижения сернистого износа двигателя / С.В. Сагин, В.Г. Солодовников // Технические науки - от теории к практике. Сб. ст. по материалам ХХХV междунар. науч.-практ. конф. № 6 (31). Новосибирск: "СибАК», 2014. С.42-48.

2. Сагин С.В. Использование топливных присадок в судовых дизелях / С.В. Сагин, Ю.В. Заблочкий // Судовые энергетические установки: науч.-техн. сб. 2012. № 30. Одесса: ОНМА. C.180-186.

3. Солодовников В.Г. Использование топлив с повышенным содержанием серы при эксплуатации судовых среднеоборотных дизелей / В.Г. Солодовников // Проблеми техніки: наукововиробничий журнал. 2014. № 2. С. 65-71.

4. Солодовников В.Г. Использование в судовых дизелях топлив различного фракиионного и структурного состава / В.Г. Солодовников // Судовые энергетические установки: науч.-техн. сб. 2014. № 33. Одесcа: ОНMA. С. 110-117. 
ВІСНИК

ОДЕСЬКОГО НАЦІОНАЛЬНОГО

МОРСЬКОГО УНІВЕРСИТЕТУ

№ 2 (62), 2020
HERALD

OF THE ODESSA NATIONAL

MARITIME UNIVERSITY

5. Заблоикий Ю.В. Исследование влияния сернистых топлив на рабочий прочесс и техническое состояние судовых среднеоборотных дизелей / Ю.В. Заблочкий, Д.В. Мацкевич // Судовые энергетические установки: науч.-техн. сб. 2014. № 33. Одесса: ОНМА. С. 60-66.

6. Лейбович Л. Растворимость водорода в смесях жидких топлива при атлосферном давлении / Л. Лейбович, Ю. Евстегнеева // Modern Engineering and Innovative Technologies, 2017. № 3(05-03). C. 46-50. https://doi.org/ 10.30890/2567-5273.201805-03-032

7. Сагін С.В. Зниження енергетичних втрат в прецизійних парах паливної апаратури суднових дизелів / С.В. Сагін // Суднові енергетичні установки: наук.-техн. зб. 2018. Вип. 38. Одеса: HУ «OMA». C. 132-142.

8. Поповский А.Ю. Комплексная оценка эксплуатационных характеристик смазочных углеводородных жидкостей / А.Ю. Поповский, С.В. Сагин // Автоматизачия судовых технических средств: науч.-техн. сб. 2014. Bып. 20. С. 74-83.

9. Заблочкий Ю.В. Исследование влияния органических покрытий на работу элементов топливной аппаратуры высокого давления судовых дизелей / Ю.В. Заблоикий // Судовые энергетические установки: науч.-техн. сб. 2015. № 35. Одесса: НУ ОМА. C. 83-92.

10. Поповский А.Ю. Оиенка эксплуатаџионных свойств смазочноохлаждающих жидкостей судовых технических средств / А.Ю. Поповский, С.В. Сагин // Автоматизачия судовых технических средств: науч.-техн. сб. 2016. Bbin. 22. C. 66-74.

11. Golikov V.A. A simple technique for identifying vessel model parameters / V.A. Golikov, V.V. Golikov, Ya. Volyanskaya, O. Mazur, O. Onishchenko // IOP Conference Series: Earth and Environmental Science. 4th International Scientific Conference SEA-CONF 2018, Published by IOP Publishing Ltd, 2018. Vol. 172. № 012010. P. 1-8. doi :10.1088/1755-1315/172/1/012010.

\section{REFERENCES}

1. Sagin, S.V., Solodovnikov, V.G. (2014) Primenenie ultrazvukovoj obrabotki topliva dlya snizheniya sernistogo iznosa dvigatelya [The use of ultrasonic fuel treatment to reduce engine sulfur wear]. Materials of the XXXV international scientific-practical conference "Technical science - from theory to practice». Novosibirsk: SibAK, no. 6(31), pp. 42-48. 
2. Sagin, S.V., Zablotsky, Yu.V. (2012) Ispolzovanie toplivnyh prisadok $v$ sudovyh dizelyah [Use of fuel additives in marine diesel engines]. Sudovye energeticheskie ustanovki: nauchno-tehnicheskij sbornik, no. 30, pp. 180-186.

3. Solodovnikov, V.G. (2014) Ispolzovanie topliv s povyshennym soderzhaniem sery pri ekspluatacii sudovyh sredneoborotnyh dizelej [Use of fuels with high sulfur content in the operation of medium-speed marine diesel engines]. Problemy texniky: naukovovyrobnychj zhurnal, no. 2, pp. 65-71.

4. Solodovnikov, V.G. (2014) Ispolzovanie v sudovyh dizelyah topliv razlichnogo frakcionnogo i strukturnogo sostava [Use in marine diesel engines of fuels of different fractional and structural composition]. Sudovye energeticheskie ustanovki: nauchno-tehnicheskij sbornik, no. 33, pp. 110-117.

5. Zablotsky, Yu.V., Matskevich, D.V. (2014) Issledovanie vliyaniya sernistyh topliv na rabochij process $i$ tehnicheskoe sostoyanie sudovyh sredneoborotnyh dizelej [Investigation of the effect of sulfur fuels on the working process and technical condition of marine medium-speed diesel engines] Sudovye energeticheskie ustanovki: nauchno-tehnicheskij sbornik, no. 33, pp. 60-66.

6. Leibovich, L., Evstegneeva, Y. (2017) Rastvorimost vodoroda v smesyah zhidkih topliva pri atmosfernom davlenii [The solubility of hydrogen in mixtures of liquid fuels at atmospheric pressure]. Modern Engineering and Innovative Technologies, vol. 3(05-03), pp. 46-50. https://doi.org/ 10.30890/2567-5273.2018-05-03-032.

7. Sagin S.V. (2018) Znyzhennya energetychnyx vtrat $v$ precyzijnyx parax palyvnoyi aparatury sudnovyx dyzeliv [Reduction of energy losses in precision steam engines of marine diesel engines] Sudovye energeticheskie ustanovki: nauchno-tehnicheskij sbornik, no. 38, pp. 132-142.

8. Popovskii, A.Yu., Sagin, S.V. (2014) Kompleksnaya ocenka ekspluatacionnyh harakteristik smazochnyh uglevodorodnyh zhidkostej [Comprehensive performance assessment of lubricating hydrocar-bon fluids]. Avtomatizaciya sudovyh tehnicheskih sredstv: nauchno-tehnicheskij sbornik, no. 20, pp. 74-83.

9. Zablotsky, Yu.V. (2015) Issledovanie vliyaniya organicheskih pokrytij na rabotu elementov toplivnoj apparatury vysokogo davleniya sudovyh dizelej [Study of the effect of organic coatings on the operation of elements of high-pressure fuel equipment of marine diesel engines]. Sudovye energeticheskie ustanovki: nauchno-tehnicheskij sbornik, no. 35, pp. 83-92. 
ВІСНИК

ОДЕСЬКОГО НАЦІОНАЛЬНОГО

МОРСЬКОГО УНІВЕРСИТЕТУ

№ 2 (62), 2020
HERALD

OF THE ODESSA NATIONAL

MARITIME UNIVERSITY

№ 2 (62), 2020

10. Popovskii, A.Yu., Sagin, S.V. (2016) Ocenka ekspluatacionnyh svojstv smazochno-ohlazhdayushih zhidkostej sudovyh tehnicheskih sredstv [Evaluation of the operational properties of cutting fluids of marine technical equipment]. Avtomatizaciya sudovyh tehnicheskih sredstv: nauchno-tehnicheskij sbornik, no. 22, pp. 66-74.

11. Golikov, V.A., Golikov, V.V., Volyanskaya, Ya., Mazur, O., Onishchenko, O. (2018) A simple technique for identifying vessel model parameters. IOP Conference Series: Earth and Environmental Science. 4th International Scientific Conference SEA-CONF, vol.172, no. 012010, pp. 1-8. doi:10.1088/17551315/172/1/012010.

Стаття надійшла до редакиії 20.04.2020

Посилання на статтю: Солодовніков В.Г. поліпшення експлуатаційних показників суднових дизелів шляхом кавітаційної обробки палива // Вісник Одеського національного морського університету: Зб. наук. праць, 2020. № 2(62). C. 120-129. DOI 10.47049/2226-1893-2020-2-120-129.

Article received 20.04.2020

Reference a JournalArtic: Solodovnikov, V. Improving the performans of marine diesel engines by cavitation treatment of the fuel // Herald of the Odessa national maritime university. 2020. 2(62), 120-129 DOI 10.47049/2226-1893-2020-2120-129. 